\section{A qualitative study of patients' motivations and expectations for dental implants}

\author{
E. B. Grey, ${ }^{1}$ D. Harcourt, ${ }^{2}$ D. O'Sullivan, ${ }^{3}$ H. Buchanan ${ }^{4}$ \\ and N. M. Kilpatrick ${ }^{5}$
}

VERIFIABLE CPD PAPER

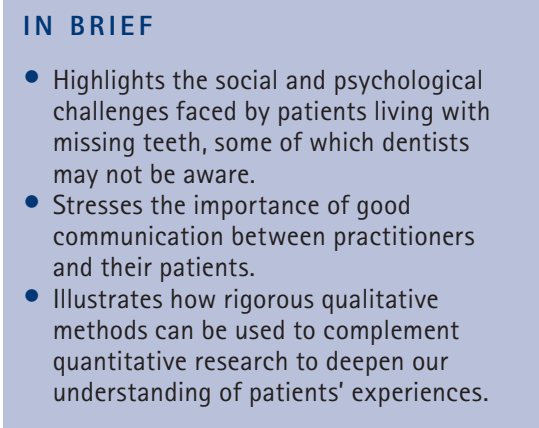

Objective To explore patients' motivations and expectations for dental implants. Design Single-setting, qualitative interview study. Subjects, setting and method Semi-structured, telephone interviews were conducted with nine patients who had consulted a restorative dental practitioner with an interest in implantology about the possibility of replacing their missing teeth with dental implants. Outcome measure Interview transcripts were subjected to thematic analysis to identify relevant themes. Results The main theme to emerge was 'normality'. Participants expected implants to restore their oralrelated quality of life to 'normal'. However, individual definitions of normality differed; some were appearance focused, while others were more concerned with functioning. Several participants who had completed implant treatment regarded their new prostheses as 'just like natural teeth'. Conclusions Patients' belief that dental implants are just like natural teeth could be cause for concern if it leads them to treat them as such, and thereby not follow the recommended specialist care they require. The findings emphasise the importance of good dental practitioner-patient communication in assessing expectations of treatment and outcomes. Further studies should explore the expectations of patients of different ages and socioeconomic backgrounds and consider ways of eliciting patients' beliefs about implants before treatment takes place.

\section{INTRODUCTION}

The proportion of edentulous adults in the UK has substantially declined from $30 \%$ in 1978 to $6 \%$ in $2009 .{ }^{1}$ However, even if tooth loss due to caries continues to decrease, periodontal disease and injury causing tooth loss will remain, meaning there will continue to be a need for replacement treatments.

Missing teeth can affect both an individual's appearance and functioning, potentially impacting on psychological and social wellbeing. ${ }^{2}$ Gaps from missing teeth are now rarely seen, due to improved oral health care. ${ }^{1}$ The wider availability of prosthetics and developments in dental technology have made straight, clean-looking

\footnotetext{
1"Department of Psychology, University of Bath, Bath: ${ }^{2}$ Centre for Appearance Research, Faculty of Health \& Life Sciences, University of the West of England, Bristol; ${ }^{3}$ School of Oral and Dental Sciences, University of Bristol, Bristol; ${ }^{4}$ Institute of Work, Health and Organisations, University of Nottingham Nottingham; ${ }^{5}$ Murdoch Children's Research Institute, Melbourne and Department of Paediatrics, University of Melbourne, Australia

${ }^{*}$ Correspondence to: Elisabeth Grey

Email: e.b.grey@bath.ac.uk
}

Online article number E1

Refereed Paper - accepted 18 September 2012

DOI: 10.1038/sj.bdj.2012.1178

${ }^{\circledR}$ British Dental Journal 2013; 214: E1 teeth more attainable and widely promoted in the media as what society considers to be an acceptable standard for dental appearance. ${ }^{3}$ As a consequence, perceived pressure to replace lost teeth and thus restore an appearance more like the 'norm' may be increasing.

Many people replace missing teeth with dentures, but attitudes towards them are less than favourable and many adults consider the thought of wearing one 'very upsetting.. In contrast, dental implants are generally viewed more favourably, in terms of stability, functionality and aesthetics ${ }^{4}$ and they are becoming increasingly available. However, in the UK they are predominantly only available privately and may cost patients considerably more than dentures obtained through the NHS. 5,6

To date, research examining patients' experiences of missing teeth and dental implants has mostly relied on quantitative measures to assess functional ability, quality of life and appearance. ${ }^{7-9}$ While such oral health-related quality of life (OHRQoL) measures provide useful data to compare pre- and post-treatment states, they explain little about participants' personal experiences and understanding of the constructs being assessed. Therefore, there have been calls for research into the meaning and significance of the issues that OHRQoL measures pertain to describe. ${ }^{10}$ Qualitative methods can complement quantitative data by providing a deeper exploration of patients' psychological and social experiences, both before and after treatment, which can shed more light on their treatment choices and resultant outcomes, including oral hygiene behaviours.

Within the existing literature, relatively little is currently known about patients' expectations of implant treatment compared with dentures. Since pre-treatment expectations strongly predict satisfaction with dental treatment outcomes, ${ }^{2}$ it is important to identify and understand what patients expect from different types of replacements and take steps to correct any misunderstandings or unrealistic expectations.

Therefore, this study sought to understand patients' motivations for seeking implants and their expectations of treatment. Rigorous qualitative methods were employed in order to gain detailed insight into patients' experiences. 


\begin{tabular}{|c|c|c|c|c|c|}
\hline Pseudonym & Age & Gender & Anterior teeth missing & Posterior teeth missing & Treatment \\
\hline Jack & 63 & M & $\begin{array}{l}\text { Maxilla: all } \\
\text { Mandible: none }\end{array}$ & $\begin{array}{l}\text { Maxilla: R4-7, L4-7 } \\
\text { Mandible: R8, L8 }\end{array}$ & 4 implant-supported maxillary denture \\
\hline Julia & 66 & $\mathrm{~F}$ & $\begin{array}{l}\text { Maxilla: R2 } \\
\text { Mandible: none }\end{array}$ & $\begin{array}{l}\text { Maxilla: none } \\
\text { Mandible: none }\end{array}$ & Single implant to replace a lateral incisor \\
\hline Kirsty & 50 & $\mathrm{~F}$ & $\begin{array}{l}\text { Maxilla: R3 } \\
\text { Mandible: none }\end{array}$ & $\begin{array}{l}\text { Maxilla: R5 + 6, L7-9 } \\
\text { Mandible: } \mathrm{R} 6+8, \mathrm{~L} 5+7\end{array}$ & Partial denture to replace maxillary teeth \\
\hline Mike & 62 & M & $\begin{array}{l}\text { Maxilla: all } \\
\text { Mandible: R3 }\end{array}$ & $\begin{array}{l}\text { Maxilla: all except R6 } \\
\text { Mandible: R5-7, L7 + } 8\end{array}$ & 4 implant-supported maxillary denture \\
\hline Nicky & 49 & $\mathrm{~F}$ & $\begin{array}{l}\text { Maxilla: none } \\
\text { Mandible: none }\end{array}$ & $\begin{array}{l}\text { Maxilla: R5-7 } \\
\text { Mandible: none }\end{array}$ & Single implant to replace maxillary R5 \\
\hline Paul & 55 & M & $\begin{array}{l}\text { Maxilla: all } \\
\text { Mandible: none }\end{array}$ & $\begin{array}{l}\text { Maxilla: all } \\
\text { Mandible: } \mathrm{R} 6+7, \mathrm{~L} 6+7\end{array}$ & $\begin{array}{l}6 \text { implant-supported maxillary denture and } \\
4 \text { implants in mandible }\end{array}$ \\
\hline Patricia & 69 & $\mathrm{~F}$ & $\begin{array}{l}\text { Maxilla: L1-3 } \\
\text { Mandible: R1 + 2, L1 }\end{array}$ & $\begin{array}{l}\text { Maxilla: L4-6 } \\
\text { Mandible: none }\end{array}$ & Several implants to replace L1-5 of maxilla \\
\hline Ruth & 60 & $\mathrm{~F}$ & $\begin{array}{l}\text { Maxilla: all } \\
\text { Mandible: R1 + 2, L1 + } 2\end{array}$ & $\begin{array}{l}\text { Maxilla: all } \\
\text { Mandible: all }\end{array}$ & $\begin{array}{l}\text { Combination of implants, crowns and bridge work in } \\
\text { both jaws }\end{array}$ \\
\hline Sue & 64 & $\mathrm{~F}$ & $\begin{array}{l}\text { Maxilla: none } \\
\text { Mandible: none }\end{array}$ & $\begin{array}{l}\text { Maxilla: R4, L6 } \\
\text { Mandible: R5 +6, L6 }\end{array}$ & 2 implants in the maxilla \\
\hline
\end{tabular}

\section{METHOD}

Adults who had consulted a restorative dental specialist with an interest in implantology (DOS) at a private dental practice in Wiltshire, UK, and who were fluent in English were eligible. All patients who met these criteria and had consulted the dentist between January 2008 and January $2011(\mathrm{n}=50)$ to discuss the possibility of implants were posted information about the study, with freepost response forms. They were eligible to participate regardless of whether or not they had opted for implant treatment: some had undergone treatment at the practice, others sought implants elsewhere and others decided against it. Participation was voluntary. Approval was gained from the research ethics committees at the University of Bath and the University of the West of England.

All interviews were conducted by telephone, a method which can elicit responses of similar quantity and quality as face-to-face interviews. ${ }^{11}$ They were conducted by the first author, following a semi-structured schedule developed by the first two authors on the basis of previous literature and with input from the other authors. Piloting ensured the acceptability, appropriateness and productivity of questions. Commensurate with the semistructured nature of the interviews, questions were added or modified as necessary to allow deeper exploration of pertinent topics. At the end of each interview the researcher relayed a summary of what she understood the participant to have said and asked them to comment on whether this was a correct representation, as recommended by Willig. ${ }^{12}$ Interviews lasted between 26 and 53 minutes. They were recorded and transcribed verbatim.

Transcripts were then analysed using QSR NVivo 9, following a six step process of thematic analysis outlined by Braun and Clarke. ${ }^{13}$ To ensure rigour, the thematic interpretation was discussed between all the authors.

\section{RESULTS}

Nine interviews were conducted (Table 1); seven participants had completed implant treatment, one was currently undergoing treatment and one had decided against them. Pseudonyms are used throughout this paper to maintain patient confidentiality. Most interviewees had been missing teeth for several years and had tried replacements such as bridges or conventional dentures before seeking implants. Only two participants (Julia and Nicky) had no prior experience of conventional dentures.

An overarching theme of 'Normality' emerged from the data, linking the subthemes of appearance and functioning (Fig. 1). All participants spoke about how missing teeth marked a change from what they deemed to be 'normal' in terms of appearance and/or functioning.

\section{Appearance}

Dental appearance was discussed in terms of its effect on how participants felt about themselves (teeth and the individual) and on how

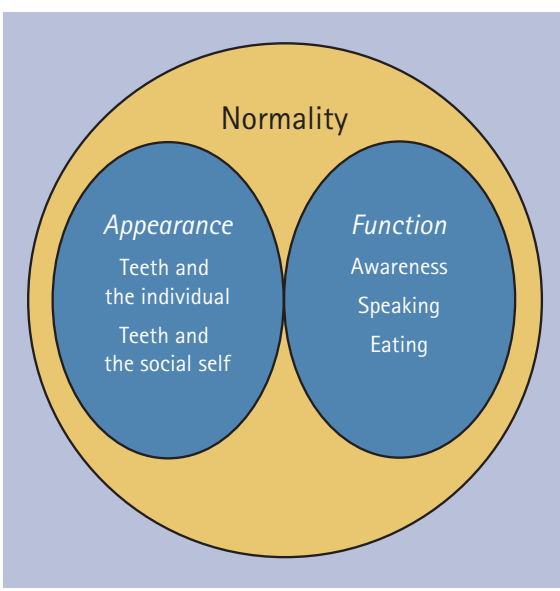

Fig. 1 Diagram of themes

participants felt and behaved in company (teeth and the social self). These two components were often but not necessarily linked.

\section{Teeth and the individual}

Many participants described how their appearance with missing teeth did not match the internal image they had of themselves (their self-image). For some, this deviation was quite distressing.

Kirsty: 'I just don't think it looks right. When you see it missing you think 'oh my God!'

The expectation that implants would restore 'normal' appearance, in part by supporting bone structure, was a reason for choosing the treatment.

Jack: 'If you've got a chance of keeping your bone structure then you keep the look of your face, and that matters to you.'

These quotes illustrate the importance individuals placed on an appearance 
matching their self-image, which in most cases was based on their appearance before teeth were missing. Interestingly, while missing teeth were not deemed acceptable, changes in dental appearance due to ageing (such as discolouration) were tolerated because they were regarded as natural and, as such, participants did not want this altered:

Sue: 'They've [implants] been made the same colour as my natural teeth, cos obviously my natural teeth aren't pure white. I've accepted that, that's how my teeth look. I didn't ask [dentist] to put me a couple of white teeth in.'

Implant treatment was seen to be restorative - participants were not seeking to improve their pre-tooth loss appearance or to look younger, rather they wished to recreate their self-image. This is noteworthy since implant treatment provides an opportunity to have teeth that differ in colour or shape to natural ones, but participants wanted as 'normal' an appearance as possible. This is illustrated by Ruth, who underwent extensive dental treatment to replace missing teeth and alter existing teeth. Although she finds the new teeth aesthetically pleasing, she is concerned that they don't seem natural:

Ruth: 'The weirdest thing now is that my teeth, they're almost too perfect. [The dentist's] done them in quite a good colour but they're so perfect. I'm quite fascinated now looking at everyone and their bad teeth - thinking 'oh they look far more natural than mine."

Rather than a desire to attain a 'perfect' smile the main concern for many was to uphold a respectable appearance which, for some, was linked to their self-evaluation,

Julia: 'It's part and parcel of your selfesteem; your awareness of how you look as a whole.'

However, for others an altered appearance with missing teeth had less of an impact. When asked if her confidence had been affected Sue replied,

Sue: 'No. I didn't think it was. Maybe, I was a little bit more aware of it. The thing is I used to forget about it a lot of the time so I probably sort of smiled and laughed and didn't give it a lot of thought.'

So, while all participants desired to return to a 'normal' appearance, the deviation from normal that came with missing teeth impacted upon them in different ways. For some, missing teeth had been detrimental to their view of themselves and implants were seen as an opportunity to restore their self esteem by returning a 'normal' appearance. However, what participants considered 'normal' and 'acceptable' varied considerably. For some, the acceptable standard was based on what they perceived as normal for themselves as an individual, while others were more influenced by their perceptions of societal expectations and of being judged negatively by others because they were missing teeth,

Paul: 'You look at somebody who's got a missing tooth and straight away you pigeon-hole them - they've got no money or they're somebody that's been in a fight, maybe at the bottom of the social ladder.'

\section{Teeth and the social self}

Being conscious of their missing teeth affected how participants felt and/or behaved around others, with some describing feeling embarrassed by gaps and poorly-fitting dentures:

Mike: 'You don't want to be seen in public. If anybody doesn't know that you haven't got the denture, you don't want them to see you without it'

This led many participants to restrain their smiles or shield their mouth when talking:

Ruth: 'Sometimes I've gone to town and completely forgotten to put my teeth in and I'd go around with my hand over my mouth, muttering apologies to people who hadn't even noticed. For me it was glaringly obvious I had this huge gap.'

Julia: 'If I wanted to laugh at something out loud I would put my hand in front of my mouth to stop people seeing what I thought was really rather nasty. Seeing that gap. I would say my confidence was slightly dented.'

Even reassurance from others that a missing or false tooth was not noticeable failed to allay embarrassment,

Ruth: 'Even if some people really reassure you, it still seems to be almost unbearably awful.'

Dental implants were seen as a way to restore a 'normal' appearance and thus enable them to behave naturally:

Julia: 'I expected that I'd return to being the person who could smile broadly and be totally unselfconscious about having this implant and return to what I considered my normal appearance.'

Participants described missing teeth as socially unacceptable because of the availability of dental care, which had limited the diversity in appearance of people's teeth in society.

Julia: 'I suppose there's an expectation that, today, we have access to dentistry so why wouldn't you go and see a dentist and keep your teeth looking good?'

They distinguished between what they considered acceptable and society's ideals for dental appearance, which were promoted by the media. This social ideal was not a concern for most participants, but some, such as Kirsty, spoke of how pervasive images of 'perfect' teeth had impacted on her view of herself.

Kirsty: 'When you see magazines, and we all know that these people in magazines are airbrushed, but they just look perfect. It just makes you feel inadequate because you haven't got these perfectly white, straight teeth.

Other participants were aware of the idealised image of straight, white teeth, but felt unaffected by it and even described it as unattractive. Mike did not want what he termed the 'Hollywood smile' because 'it doesn't actually look natural'.

In summary, one of the two main drivers behind seeking dental implants was the impact on appearance of missing teeth. This was expressed in terms of participants' self-esteem, society's perceptions of people with missing teeth and the behavioural changes that individuals adopted to disguise their altered appearance. Implants were considered to be a way to resolve these issues.

\section{Function}

As well as the effect of an altered appearance, participants also described how missing teeth (and dentures) had impacted on function, particularly eating and speaking.

Ruth: 'I hadn't been able to chew. I hadn't been able to really enjoy food. I was just eating mush. It was just really boring and limiting.'

The inconvenience of dentures was also mentioned, for example if food got caught beneath them or the ability to taste food was impaired. Speech was also a problem with ill-fitting dentures and for Jack this was the trigger to seek implants: 
Jack: 'You get to the point then where you realise you're starting to talk with a lisp because you're trying to keep your denture up with your tongue while you're talking.

Participants described how these problems were intolerable and had led them to become very self-conscious of not eating or speaking 'normally'. Natural teeth were viewed as being like other bodily organs; they function without the individual being aware. In contrast, participants were almost constantly aware of their mouth when teeth were missing. This awareness, together with adjusting their lifestyle to accommodate functional problems, was 'inconvenient' and dental implants were considered a convenient means of restoring oral function to normal.

Overall, missing teeth and/or wearing dentures increased awareness of the mouth, whether due to the impact on functioning or a concern about appearance, and this marked a shift away from what participants considered 'normal'. Dental implants were seen as a means of re-establishing normality in everyday life:

Sue: 'I knew it was going to be nicer; more comfortable to eat, and when I looked in the mirror they would look like my natural teeth, so no one would know that they weren't my natural teeth.'

Interestingly, while dentures were seen as 'unnatural', implants were not, despite also being, technically, unnatural. The belief that implants would be 'like having your tooth again' (Kirsty) was common to all.

The desire to return to normality was, therefore, the driving force behind decisions to seek implants, which were perceived as the best alternative to natural teeth. Although participants varied in the degree to which they were motivated either by appearance or function, both factors were mentioned by all.

\section{DISCUSSION}

Although some quantitative studies have examined changes in quality of life after implant treatment, until now, very little research has examined patients' expectations of dental implants. Given the exploratory nature of this research we chose to use qualitative methods, which provide detailed insights into underlying issues and identify a broad range of potentially important factors for further study. ${ }^{14}$ Participants in this study expected implants to overcome the various functional, social and psychological difficulties they had experienced with missing teeth and/or conventional dentures, and thereby restore 'normality'. Allen et al. ${ }^{15}$ also found that many edentulous adults expected implants would return their chewing ability to that of a fully dentate individual, but did not examine expectations around social and psychological issues. The fixed nature of implants was particularly appealing as having to remove an appliance for cleaning or to taste/eat more easily was considered very inconvenient and embarrassing. Furuyama and colleagues $^{16}$ reported significantly better oral-health related quality of life in patients with implant-supported fixed rather than removable partial dentures since, as well as being more convenient to maintain, a fixed prosthesis felt more like a natural body part and thus restored a sense of normal functioning.

Participants in the current study expected implants would restore 'normal' appearance and enable them to feel more confident and relaxed in social interactions, an expectation which has also been reported among patients seeking veneers. ${ }^{17}$ Contrary to Kent, ${ }^{18}$ who found aesthetic concerns were insufficient motivators for implant treatment, some participants in the current study described opting for implants for the sake of appearance. This may be indicative of the increasing importance society seems to place on dental appearance ${ }^{19}$ and perceived pressure to conform to these societal ideals. While marketing materials tend to focus on the ability of implants and other cosmetic dental procedures to achieve the 'Hollywood smile', participants in this study were striving for an appearance they considered to be acceptable, not to increase attractiveness. However, it is possible that the social aesthetic ideal has influenced what participants deemed acceptable. This study is, to our knowledge, the first to explore patients' desire for 'normality' as being a motivation for and expectation of dental implant treatment. It adds to the small body of research in other areas, such as breast reconstruction, ${ }^{20}$ in which patients have sought to restore 'natural' appearance and functioning through the use of invasive procedures.

The desire for a natural appearance may also reflect the age of the current sample.
The participants were at least 49-yearsold, which is representative of the implant patient population since the cost of implants necessitates disposable income that tends to come with age. ${ }^{21}$ It has been suggested that, as they age, people strive less to look like the idealised images in the media, becoming more realistic in their appearance aims, ${ }^{22}$ and more satisfied with their dental appearance, despite physiological changes (for example, yellowing of teeth) that cause teeth to drift further from the social ideal.

It would be interesting to explore whether the presence of natural teeth next to prosthetic teeth affects patients' satisfaction with their treatment outcomes. Ruth mentioned that her new teeth were 'almost too good', however, her natural mandibular canines were still present and might have served as a reminder of how her teeth looked pre-treatment. The extent to which dental implants are viewed and/ or accepted by patients as part of their body may also be related to their original motivation for treatment. For example, if implants were sought mainly for functional purposes the presence of natural teeth next to an implant might not alter the patient's satisfaction. However, the range of dental status among the participants in this study and the different treatment stages they were at means it is not possible to draw further conclusions by comparing patients seeking only to fill gaps between natural teeth and those wanting to replace all the teeth in one (or both) jaw(s).

\section{LIMITATIONS}

This was a small, opportunity sample and participants varied in the number and type of teeth they had lost, with some likely to have been more noticeable or important for functioning than others. Thus the findings may not be representative of the wider population and further studies should explore the expectations of patients of different ages and socioeconomic backgrounds in order to inform future service provision.

Participants retrospectively described their experiences of living with missing teeth, which may have influenced their recall and interpretation of events, perhaps in an effort to justify their treatment decisions. Longitudinal studies of 
patients undergoing reconstructive dental procedures have found they tend to retrospectively rate their pre-treatment quality of life lower than they did at the time. ${ }^{8}$ Longitudinal studies following patients from their initial tooth loss through the course of treatment would give a valuable, in-depth understanding of their experience of missing teeth, reasons for treatment choice and outcomes.

\section{IMPLICATIONS}

This study highlights how patients have different motivations for and expectations of dental implants, with an overriding desire to regain 'normality'. This emphasises the importance of good clinician-patient communication in assessing patients' expectations. In order to maximise patient satisfaction, the clinician needs to elicit exactly what each patient expects and assess whether this is realistic or whether an alternative treatment may be preferable in meeting their needs. Ways of helping dentists elicit patients' expectations need to be developed and evaluated.

The belief that dental implants are 'just like having natural teeth' is important in clinical terms since patients holding this view may be more inclined to treat their implants in the same way as they would natural teeth which, for many, may not entail the thorough cleaning procedures imperative for implant longevity. Given that individuals seeking implants may have lost their natural teeth due to poor oral hygiene and periodontal disease, perceiving dental implants as akin to natural teeth may bring about a return to previous inadequate oral hygiene routines. Adequate oral hygiene measures for dental implants have been found to be difficult to achieve and sustain, and in turn are associated with the development of peri-implant inflammatory disease, leading to implant failure. ${ }^{23,24}$ Ensuring that patients understand the different demands of implants over natural teeth and the need for longterm rigorous home maintenance may improve outcomes.

The authors would like to thank the participants for their involvement and support of this study.

1. Hellyer P H. The older dental patient - who cares? Br Dent J 2011; 211: 109-111.

2. Roumanas E D. The Social solution - denture esthetics, phonetics, and function. J Prosthodont 2009: 18: 112-115.

3. Meadows L M, Verdi A J, Crabtree B F. Keeping up appearances: using qualitative research to enhance knowledge of dental practice. J Dent Educ 2003; 67: 981-990.

4. Rustemeyer J, Bremerich A. Patients' knowledge and expectations regarding dental implants: assessment by questionnaire. Int J Oral Maxillofac Surg 2007; 36: 814-817.

5. Takanashi Y, Penrod J R, Lund J P, Feine J S. A cost comparison of mandibular two-implant overdenture and conventional denture treatment. Int J Prosthodont 2004; 17: 181-186.

6. NHS choices. Dental treatments. Online information available at http://www.nhs.uk/Livewell/dentalhealth/Pages/Dentaltreatments.aspx (accessed November 2012).

7. Erkapers M, Ekstrand K, Baer R A, Toljanic J A, Thor A. Patient satisfaction following dental implant treatment with immediate loading in the edentulous atrophic maxilla. Int J Oral Maxillofac Implants 2011; 26: 356-364.

8. Thomason J M, Heydecke G, Feine J S, Ellis J S. How do patients perceive the benefit of reconstructive dentistry with regard to oral health-related quality of life and patient satisfaction? A systematic review. Clin Oral Implants Res 2007; 18(Suppl 3): 168-188.
9. Pavel K, Seydlova M, Dostalova T et al. Dental implants and improvement of oral health-related quality of life. Community Dent Oral Epidemiol, 2012; 40(Suppl 1): 65-70.

10. Locker D, Allen F. What do measures of 'oral health-related quality of life' actually measure? Community Dent Oral Epidemiol 2007; 35: 401-411.

11. Sturges J E, Hanrahan K J. Comparing telephone and face-to-face qualitative interviewing: a research note. Qual Res 2004; 4: 107-118.

12. Willig C. Introducing qualitative research in psychology. 2nd ed. Maidenhead: Open University Press, 2008.

13. Braun V, Clarke V. Using thematic analysis in psychology. Qualitative Res Psych 2006; 3: 77-101.

14. Smith J A. Qualitative psychology: a practical guide to research methods. 2nd ed. London: Sage Publications Ltd, 2007.

15. Allen P F, McMillan A S, Walshaw D. Patient expectations of oral implant-retained prostheses in a UK dental hospital. Br Dent J 1999; 186: 80-84.

16. Furuyama C, Takaba M, Inukai M, Mulligan R, Igarashi Y, Baba K. Oral health-related quality of life in patients treated by implant-supported fixed dentures and removable partial dentures. Clin Oral Implants Res 2012; 23: 958-962.

17. Davis L G, Ashworth P D, Spriggs L S. Psychological effects of aesthetic dental treatment. J Dent 1998; 26: 547-554.

18. Kent G. Effects of osseointegrated implants on psychological and social wellbeing: a literature review. J Prosthet Dent 1992; 68: 515-518.

19. Morar A, Stein E. A method of assessing facial profile attractiveness and its application in comparing the aesthetic preferences of two samples of South Africans. J Orthodont 2011; 38: 99-106.

20. Denford S, Harcourt D, Rubin L, Pusic A. Understanding normality: a qualitative analysis of breast cancer patients' concepts of normality after mastectomy and reconstructive surgery. Psychooncology 2011; 20: 553-558.

21. Mundt T, Polzer I, Samietz $S$ et al. Socioeconomic indicators and prosthetic replacement of missing teeth in a working-age population - results of the Study of Health in Pomerania (SHIP). Community Dent Oral Epidemiol 2009; 37: 104-115.

22. Rumsey N, Harcourt D. The psychology of appearance. Maidenhead: Open University Press, 2005.

23. Ferreira S D, Silva G L, Cortelli J R, Costa J E, Costa $F \mathrm{O}$. Prevalence and risk variables for peri-implant disease in Brazilian subjects. J Clin Periodontol 2006; 33: 929-935.

24. Serino G, Ström C. Peri-implantitis in partially edentulous patients: association with inadequate plaque control. Clin Oral Implants Res, 2009; 20: 169-174. 